\title{
APLICAÇÃO DE MODELO DE TUTORIA PROATIVA NA MODALIDADE SEMIPRESENCIAL DE ENSINO A DISTÂNCIA UTILIZANDO FERRAMENTAS DE INTERATIVIDADE E PERSONALIZAÇÃO
}

\author{
Juliana Aguiar | juliana.aguiar@gmail.com \\ Mestre em Biociências e Biotecnologia pela Universidade Estadual do Norte Fluminense Darcy Ribeiro - UENF. UENF/CEDERJ/UAB \\ Cristina Ferreira | cristtina_sf@yahoo.com.br \\ Bacharel em Ciências Biológicas pela Universidade Estadual do Norte Fluminense Darcy Ribeiro - UENF. UENF/CEDERJ/UAB. \\ Ana Beatriz Garcia | garcia.anabeatriz@gmail.com \\ Doutora em Genética Molecular de Plantas, pela Reiksuniversiteit Gent, Bélgica. Professora Associada da Universidade Estadual do \\ Norte Fluminense Darcy Ribeiro - UENF. UENF/CEDERJ/UAB.
}

\section{Resumo}

A Educação a Distância (EAD) é a modalidade educacional em que o processo de ensino-aprendizagem ocorre com auxílio de meios e tecnologias de informação e comunicação (TICs) permitindo a alunos e professores desenvolverem atividades educacionais em lugares ou tempos diversos.

Durante os anos de 2008 e 2009, a disciplina Instrumentação para o Ensino em Genética, do curso de Licenciatura em Ciências Biológicas do Consórcio CEDERJ, foi utilizada como alvo de estudo. O objetivo do presente trabalho é apresentar um modelo de tutoria proativa utilizando ferramentas de interatividade e personalização do processo de ensino-aprendizagem na modalidade semipresencial buscando a maior interação e motivação do aprendiz, além de estreitar os laços afetivos entre aprendiz e tutoria.

Ações presenciais e a distância foram propostas ao diagnosticar o perfil dos aprendizes. $\mathrm{O}$ estímulo, a interatividade e a personalização do processo de ensino-aprendizagem permitiram uma diminuição no índice de abandono no período avaliado. A participação nos encontros presenciais contribuiu para aumentar a afetividade. Além disso, observou-se um aumento da participação em encontros virtuais apresentada em número de aprendizes presentes nos encontros virtuais e a melhora no desempenho, apresentada em média de notas.

Considerou-se que o aprendiz deve se sentir parte ativa, buscando, com auxílio da tutoria, a melhor forma de utilizar suas habilidades e competências para um maior aproveitamento.

\section{Palavras-chave}

Interatividade. Afetividade. Tutoria proativa. Personalização. EAD. 
APPLICATION OF THE PROACTIVE TUTORIAL MODEL IN THE SEMIPRESENTIAL DISTANCE LEARNING MODALITY USING INTERACTIVITY AND PERSONALIZATION TOOLS

\section{Abstract}

Distance Education (DE) is the educational modality whereby the teaching-learning process occurs with the aid of media and information and communication technologies (ICTs), enabling students and teachers to carry out educational activities in different places or times. During 2008 and 2009 the subject Instrumentation for Teaching Genetics, part of the CEDERJ Consortium Teacher Training in Biological Sciences course, was used as a study target. The aim of this paper is to present a model of proactive tutoring using interactive and personalization tools of the teaching-learning process in a semi-distance educational modality, seeking a greater interaction with and motivation of the learner, in addition to strengthening the emotional bonds between pupil and tutor. Face-to-face and long distance approaches were proposed as learners' profiles were diagnosed. Positive stimulus, interactivity and personalization of the teaching-learning process led to a reduction in student dropout rates during the period analyzed. Attendance in face-to-face encounters helped to increase affectivity. Furthermore, there was an increase in virtual meeting attendance reflected by the number of learners attending virtual encounters, and improved performance, shown by a higher grade average. It was considered that the learner should feel that he is an active part of the process, employing tutoring to find the best way to use his skills and talents to maximize learning.

\section{Keywords}

Interactivity. Affectivity. Proactive tutoring. Personalization. DE.

\section{Resumen}

La Educaccion a Distancia (EAD) es la modalidad educacional en que el proceso enseñanza-aprendizaje ocurre con el auxilio de medios y tecnologías de información y comunicación (TICs) permitiendo a alumnos y profesores desarrollar actividades educacionales en lugares o tiempos diversos.
Durante los años 2008 y 2009 la asignatura Instrumentación para la Enseñanza de Genética, del curso de Profesorado en Ciencias Biológicas del consorcio CEDERJ, fue utilizada como objeto de estudio. El objetivo del presente trabajo es presentar un modelo de tutoría proactiva utilizando herramientas de interactividad y personalización del proceso enseñanza-aprendizaje en la modalidad semipresencial, buscando una mayor interacción y motivación del aprendiz, así como estrechar los lazos afectivos entre aprendiz y tutoría.

Acciones presenciales y a distancia fueron propuestas al diagnosticar el perfil de los estudiantes. El estímulo, la interactividad y la personalización del proceso enseñanza-aprendizaje permitieron una disminución del índice de abandono en el período evaluado. La participación en los encuentros presenciales contribuyó para aumentar la afectividad. Además se observó un aumento de la participación en encuentros virtuales observada en el número de estudiantes presentes en los encuentros virtuales, y la mejoría en el desempeño, a través del promedio de las notas.

Se considera que el aprendiz debe sentirse parte activa, buscando con el auxilio de la tutoría, la mejor forma de utilizar sus habilidades y competencias para un mayor rendimiento.

\section{Palavras-Clave}

Interactividad. Afectividad. Tutoria proactiva. Personalización. EAD.

\section{Introdução}

\subsection{Considerações gerais sobre EAD}

De acordo com o Decreto 5.622, publicado em dezembro de 2005, a Educação a Distância (EAD) é a modalidade educacional na qual a mediação didáticopedagógica nos processos de ensino e aprendizagem ocorre com a utilização de meios e Tecnologias de Informação e Comunicação (TICs), em que o desenvolvimento de atividades educativas é realizado em lugares ou tempos diversos.

Nesse sentido, a EAD pôde ser dividida em modelos nos quais as aulas são aplicadas em regime semipresencial ou a completa distância. Esses modelos incluem as aulas por correspondência, teleaula, videoaula e aula Web (BASTOS, 2003). Dessa forma, podemos visu- 
alizar a evolução de EAD de acordo com os avanços tecnológicos obtidos ao longo do tempo. Atualmente, os meios mais utilizados em EAD são: impresso, teleconferência, chat, fóruns de discussão, correio eletrônico, além de plataformas de ambientes virtuais de aprendizagem (FLORIANO et al., 2005).

Os avanços em EAD seguem parâmetros tecnológicos, culturais e sociais. A tecnologia ocupa papel essencial na influência sobre a EAD, sendo a internet o instrumento que propicia uma maior interação entre alunos/aprendizes e professores/tutores (DAHMER, 2006). Culturalmente, o ensino a distância é visto muitas vezes de forma negativa, sendo considerado insatisfatório quando comparado com a modalidade presencial. O papel social da EAD como uma política pública é visto muitas vezes como uma medida paliativa no que diz respeito a levar ensino a regiões distantes dos centros urbanos, recebendo muitas críticas no que diz respeito ao efetivo aprendizado do estudante (BELLONI, 1999; RIOS e PIMENTEL, 2007).

Entretanto, os resultados apresentados por alunos de $\mathrm{EAD}$ quando comparados aos alunos da modalidade presencial mostram a evolução dessa modalidade de ensino permitindo uma maior aceitação cultural e social. No cenário atual, a EAD vem sofrendo transformações a partir de mudanças de valores nos quais a diversidade cultural é presente, em sua contextualização, de saberes e conhecimentos. A EAD, além de propiciar uma contextualização social variada, permite uma reflexão sobre a aprendizagem (CLOSS et al., 2008)

A EAD é tida como uma modalidade que possui maior alcance, razão custo/benefício mais favorável e maior flexibilidade (para os tutores e aprendizes), além da personalização da EAD em nível tal que algumas vezes chega à individualização (CHAVES, 1999).

A educação, seja ela presencial ou a distância, deve propiciar ao estudante alguns aspectos fundamentais como: consciência crítica, criativa e participativa; formação sólida e vinculação da teoria com a prática, contextualizada nos aspectos social, econômico, político e cultural (RIOS e PIMENTEL, 2007). O processo de ensino-aprendizagem necessita de um espaço interativo, confiável, onde a reciprocidade na construção do conhecimento é fundamental.
Nesse contexto a Educação a Distância tem como base o compartilhamento do conhecimento, a prática pedagógica dialógica, a autonomia, a autoaprendizagem, a interatividade, o trabalho colaborativo e a avaliação com foco na formação. Processos que valorizam as potencialidades do aprendiz.

A Comunicação Mediada por Computador (CMC) permitiu a exploração de novas abordagens de ensinoaprendizagem em EAD, diferentes da abordagem tradicional baseada na transmissão passiva de informações ao aprendiz. Com os recursos introduzidos pela CMC tornou-se possível explorar abordagens baseadas na colaboração, na construção de conhecimentos e na avaliação formativa do aprendiz. Dessa forma, a EAD passa a ser vista como uma oportunidade de mudança no quadro educacional existente (VALENTE, 2000).

Assim, as inovações no âmbito da Educação a Distância podem contribuir com os sistemas tradicionais de educação, fazendo com que ocorra uma inovação não só tecnológica como metodológica (BELLONI, 1999; MORAN, 2009c).

Não há, porém, uma discussão sobre a substituição de uma modalidade de ensino pela outra. Moran (2003) afirma que a inserção de elementos tecnológicos na educação presencial para que o aprendiz busque mais a aprendizagem na ausência do professor possibilita uma visão de autonomia e valorização da aprendizagem. Por outro lado, Moran (2004) também apresenta a necessidade de encontros presenciais em cursos de EAD para aumentar os laços de confiança entre tutor e aprendiz além de motivar e aumentar a interação do aprendiz. Assim, verifica-se a necessidade de um equilíbrio para a educação com propostas pedagógicas que fortaleça o processo de ensino-aprendizagem (CALABRI, 2009).

Nesse sentido, estratégias metodológicas foram desenvolvidas a fim de permitir a presença temporal do tutor em cursos de EAD, caracterizando a educação semipresencial. Segundo Voigt (2007), essa modalidade de EAD pode ser considerada como uma ponte que liga a modalidade presencial clássica com a moderna Educação a Distância, possibilitando usufruir das vantagens das duas modalidades.

$\mathrm{Na}$ modalidade semipresencial, estudantes e professores estão separados fisicamente em determina- 
dos momentos da disciplina, mas interligados por meio de comunicação, interação e nas aulas presenciais (MORAN, 2009a). Esta interligação permite a retomada dos conteúdos estudados nos momentos não presenciais nas aulas presenciais, estimulando os processos de ensino e aprendizagem (OLIVEIRA, 2007). Por tais especificidades, a semipresencialidade torna-se um elemento a mais de flexibilização curricular, no que diz respeito às condições individuais de cada estudante, ao ritmo de aprendizagem, ao local e ao tempo de dedicação aos estudos (PETERS, 2004; MORAN, 2009b).

O sucesso da modalidade semipresencial é dado em grande parte pelo desempenho do professor/tutor durante o encontro (tutoria) presencial. Assim, é essencial que o professor/tutor possua, entre outras qualidades, facilidade de comunicação, dinamismo, criatividade, liderança e iniciativa para atuar como facilitador, junto ao grupo de aprendizes, sendo caracterizado como um "orientador" da aprendizagem, com tarefas distintas do professor convencional (SOUZA, 2004).

Ao tutor não cabe a tarefa de transmitir conteúdos de forma passiva, mas a de reforçar o processo de autoaprendizagem indicando os possíveis caminhos para que o aprendiz alcance os objetivos, verificando os problemas de aprendizagem, explorando as potencialidades individuais e estabelecendo uma relação de confiança (SOUZA, 2004).

Dessa forma, à medida que o processo de aprendizagem se efetiva, a relação do aluno com o tutor muda. Estreitam-se e aprofundam-se os laços afetivos, o que propicia a permeabilidade educativa em direção a uma maior autonomia, liberdade e diferenciação (SOUZA, 2004)

A permanência do discente em cursos EAD demanda uma postura proativa, com estudos que apontem o perfil individualizado dos estudantes ingressantes, as suas interações com a estrutura de ensino e com os colegas, permitindo monitorar e melhorar o desempenho acadêmico dos discentes a partir, principalmente, da ação tutorial motivadora (GAIOSO, 2005).

A educação proativa tem como característica uma amplitude de visão e um imediatismo de ação focado na constante análise da metodologia empregada, nas dificuldades dos aprendizes e nos pontos que podem ser aperfeiçoados, estando ligados ao contínuo aperfeiçoamento (CRIVELARO, 2009). No conceito de proatividade pode-se incluir: prontidão, antecipação, perspicácia, senso de urgência, iniciativa, agilidade, responsabilidade e consistência, termos que levam ao comprometimento com o objeto de trabalho (NAVARRO, 2008). A tutoria proativa tenta propiciar o máximo de conhecimento aos aprendizes, permitindo que esses possuam uma visão ampla e crítica do processo de ensino-aprendizagem.

Em cursos a distância, o professor-tutor é aquele que faz a mediação entre os conteúdos e os aprendizes (BENETTI et al., 2008) favorecendo a autonomia da aprendizagem, e a consciência da necessidade de desenvolver sua autoaprendizagem. Essa consciência permite uma construção dinâmica do conhecimento, na qual a interação tutor-aprendiz e aprendiz-aprendiz ocorra, estabelecendo uma rede colaborativa de saberes (RIOS e PIMENTEL, 2007)

Além da construção do conhecimento individual, a construção coletiva de conhecimento é de grande importância para o processo de ensino-aprendizagem em EAD. A formação de grupos para o desenvolvimento de atividades, as discussões em fóruns e salas de encontros virtuais desenvolvem o conhecimento coletivo pelo exercício da aprendizagem colaborativa (PRATT e PALLOFF, 2004; BARBOSA, 2008).

A aprendizagem colaborativa apresenta características e elementos que favorecem a troca de informações e a negociação de conflitos com a troca de ideias, a argumentação e a reflexão oferecendo recursos para a aprendizagem individual e coletiva (ALCÂNTARA, SIQUEIRA e VALASKI, 2004). Espera-se que além de adquirir conhecimento consigam se relacionar, compartilhar opiniões e compreender a diversidade de ideias e de interpretações (JOHNSON e JOHNSON, 1997). A aprendizagem colaborativa deve prover meios que possibilitem $e$ estimulem a participação ativa dos aprendizes na construção de novos conhecimentos e que os mesmos tomem consciência da importância da contribuição individual no sucesso coletivo (ALCÂNTARA, SIQUEIRA e VALASKI, 2004).

O desempenho do aluno em atividades colaborativas pode ser usado como base para a avaliação 
individual e do grupo. Dessa forma, no processo avaliativo os professores/tutores consideram a construção individual de conhecimento como, também, o trabalho coletivo, relatórios de autoavaliação, avaliação coletiva e individual, expressão oral e escrita dos aprendizes no desenvolvimento das atividades e níveis de interação com as ferramentas de interação (VASCONCELOS et al., 2008).

A avaliação no ambiente virtual de aprendizagem (AVA) deve considerar as oportunidades oferecidas aos aprendizes para discussão e trabalho em grupo, a organização e o acesso ao conteúdo, e a facilidade de navegação do aprendiz (LAGUARDIA, PORTELA e VASCONCELLOS, 2007).

Segundo Vasconcelos e colaboradores (2008), a avaliação não deve medir apenas a quantidade de conhecimentos adquiridos pelo aluno e sim considerar seu histórico durante o curso sendo feita uma avaliação constante que permita traçar estratégias para ajudá-lo a construir seus conhecimentos, focando na formação do indivíduo como profissional e cidadão, contemplando as funções diagnóstica e formativa.

Apesar dos variados recursos disponíveis em AVAs, a avaliação da aprendizagem ainda é um desafio a ser superado. O MEC (1998) fala em avaliações presenciais, o que contradiz os projetos pedagógicos de muitos cursos construtivistas e interacionistas, mas a avaliação presencial não necessariamente precisa ser uma prova com ação verificacionista (VASCONCELOS et al., 2008; MORAN, 2009c). Poderiam ser realizadas diferentes atividades como seminários, apresentação de resultados de projetos desenvolvidos em grupos, discussões orais, sendo mais um exercício da construção coletiva do conhecimento. Bassani e Behar (2006) destacam que a avaliação da aprendizagem em AVAs deve levar em consideração a avaliação por meio de testes online, a produção individual dos aprendizes $e$ a análise das interações entre aprendizes a partir de mensagens postadas/trocadas no ambiente virtual.

Dessa forma, a avaliação formativa pode ser efetuada utilizando-se ferramentas síncronas (chat) $e$ assíncronas (lista de discussão, fórum). O chat possibilita a avaliação da capacidade de resposta imediata a questões propostas, e as habilidades de síntese, análise, avaliação e senso crítico. A avaliação via fó- rum, avalia a capacidade de autoaprendizagem, pois essa ferramenta permite que os aprendizes leiam as respostas de seus colegas, pesquisem com maior cuidado o assunto e elaborem suas respostas (BASSANI e BEHAR, 2006; SILVA e SILVA, 2008).

O processo avaliativo deve, além de contribuir para o processo de formação do indivíduo (SILVA e SILVA, 2008), servir de orientação para que o professor realize ajustes em suas estratégias didáticas, a fim de adequar melhor sua metodologia e aumentar a reposta do aluno ao processo de ensino-aprendizagem (LAGUARDIA, PORTELA e VASCONCELLOS, 2007; VASCONCELOS et al., 2008).

\subsection{Consórcio CEDERJ}

Após a adoção da EAD em unidade universitária, começam a surgir consórcios entre universidades, assim como propostas de parcerias entre universidades e governos estaduais e municipais para viabilizar cursos a distância com apoio interinstitucional (MARTINS, 2006).

A criação, em 2000, de grandes consórcios nacionais e estaduais de universidades públicas (UniRede, CEDERJ e o Projeto Veredas em Minas Gerais) é exemplo bem-sucedidos de colaboração interinstitucional, importante para o Ensino Superior a Distância

O Consórcio CEDERJ reúne seis universidades do estado do Rio de Janeiro, UERJ, UENF, UNIRIO, UFRJ, UFF e UFRRJ, a fim de levar a diversas regiões do estado Ensino Superior para formação de profissionais qualificados.

O CEDERJ conta com um modelo de EAD baseado na educação semipresencial associado ao modelo Web que permite a permanência da figura do professor-tutor em tutorias presenciais favorecendo o processo de autoaprendizagem. No modelo adotado, os alunos/aprendizes são organizados em polos, o que aproxima a universidade de regiões mais distantes.

O Ambiente de Aprendizagem a Distância dos cursos de graduação do Consórcio CEDERJ é desenvolvido na concepção de uma abordagem construtivista e é viabilizado na Web através da Plataforma CEDERJ1. Costa e Franco (2005) destacam como aspectos importantes de uma AVA a autonomia do estudante, a interatividade e a aprendizagem colaborativa. 
O objetivo do Consórcio CEDERJ é a formação integral dos alunos/aprendizes, para que se transformem em produtores de conhecimento e não em meros receptores de informações. A proposta é realizar cursos de nível superior a distância que ofereçam essa autonomia de estudo, utilizando-se a experiência educativa das universidades consorciadas.

No Consórcio CEDERJ, a competência acadêmica dos cursos está a cargo dos docentes das universidades. São eles que preparam o projeto político e pedagógico dos cursos, o conteúdo do material didático, cuidam da tutoria e da avaliação.

\subsection{Alvo de estudo}

Instrumentação para o Ensino de Genética (Instrugen) é uma das disciplinas obrigatórias oferecidas pelo curso de Licenciatura em Ciências Biológicas no âmbito do Consórcio CEDERJ.

A disciplina Instrugen foi proposta como um momento de reflexão e criação para um melhor aproveitamento da maneira como os conteúdos serão trabalhados durante a prática pedagógica do professor de Ciências e Biologia na Educação Básica e não como uma disciplina de didática específica para Genética. Nesta disciplina os assuntos são apresentados gradativamente à medida que os trabalhos são realizados $e$ entregues. Não é uma disciplina estanque com módulos e aulas, mas sim um conjunto de atividades que são construídas tendo como base a troca de informações e as discussões decorrentes da interatividade entre tutores/mediadores e aprendizes.

A disciplina foi desenhada como modelo para o estabelecimento de uma metodologia em $\mathrm{EAD}$ que visa à construção do conhecimento e à formação de um educador com uma visão ampla, capaz de aplicar o conteúdo de Genética e Biologia Molecular de forma clara e adequada ao seu público-alvo, capaz ainda de pensar em situações cotidianas aplicadas ao contexto da disciplina. A metodologia utilizou um modelo de tutoria proativa, a qual estimulou ampla participação dos aprendizes. Estes utilizaram a plataforma CEDERJ como "sala de aula", que dispõe de diversas ferramentas de interatividade assíncronas - e-mail, Sala de Tutoria, Fórum e Atividades - e síncronas - Salas de Conferência (chat), ambiente online usado para plantões de tutoria, encontros virtuais com convidados e de grupos de aprendizes interpolos.

$\mathrm{O}$ uso de ferramentas da AVA (plataforma CEDERJ) permite o desenvolvimento de atividades individuais ou em grupo, fazendo uso de ferramentas de interação como chat $e$ fóruns, estimulando a construção coletiva do conhecimento. Além da AVA a disciplina utiliza o telefone 0800 e o e-mail como ferramentas de interação.

As ferramentas são usadas para incentivar a interação tutor/aprendiz e aprendiz/aprendiz, fazendo com que, através da aprendizagem colaborativa, contribuam uns com os outros. Assim estimulou-se a construção do saber coletivo. Utilizou-se também a avaliação formativa em cada uma das atividades propostas, sendo uma avaliação contínua na qual o aprendiz consegue visualizar sua evolução na disciplina.

O objetivo do presente trabalho é apresentar um modelo de tutoria proativa utilizando ferramentas de interatividade e personalização do processo ensinoaprendizagem na modalidade semipresencial buscando a maior interação e motivação do aprendiz, além de estreitar os laços afetivos entre aprendiz e tutoria.

\section{Metodologia}

O modelo pedagógico da disciplina, baseado na proposta de tutoria proativa, na aprendizagem colaborativa, no incentivo à interatividade e na avaliação formativa, visa a que o processo de ensino aprendizagem seja satisfatório.

Para isso, foram disponibilizados, semestralmente, no ambiente virtual de aprendizagem (AVA - http://novaplataforma.cederj.edu.br/mailmarketing/files/livroguiadaplataforma.pdf), os calendários (atividades, encontro presencial,) e o guia da disciplina (objetivos, propostas e método avaliativo). As ações presenciais e a distância utilizadas no modelo de tutoria proativa (Figura 1) foram realizadas através de encontro presencial $e$ de ferramentas assíncronas e síncronas. Em todas as ações realizadas a tutoria atuou como mediadora, além de personalizar o atendimento a fim de se aproximar do aprendiz de forma a atender suas necessidades. A tutoria sempre se colocou também como aprendiz em situações determinantes. O tratamento individualizado valorizou as competências e habilidades de cada aprendiz sempre com linguagem incentivadora, motivadora, aproximando o mesmo da disciplina e da tutoria. 


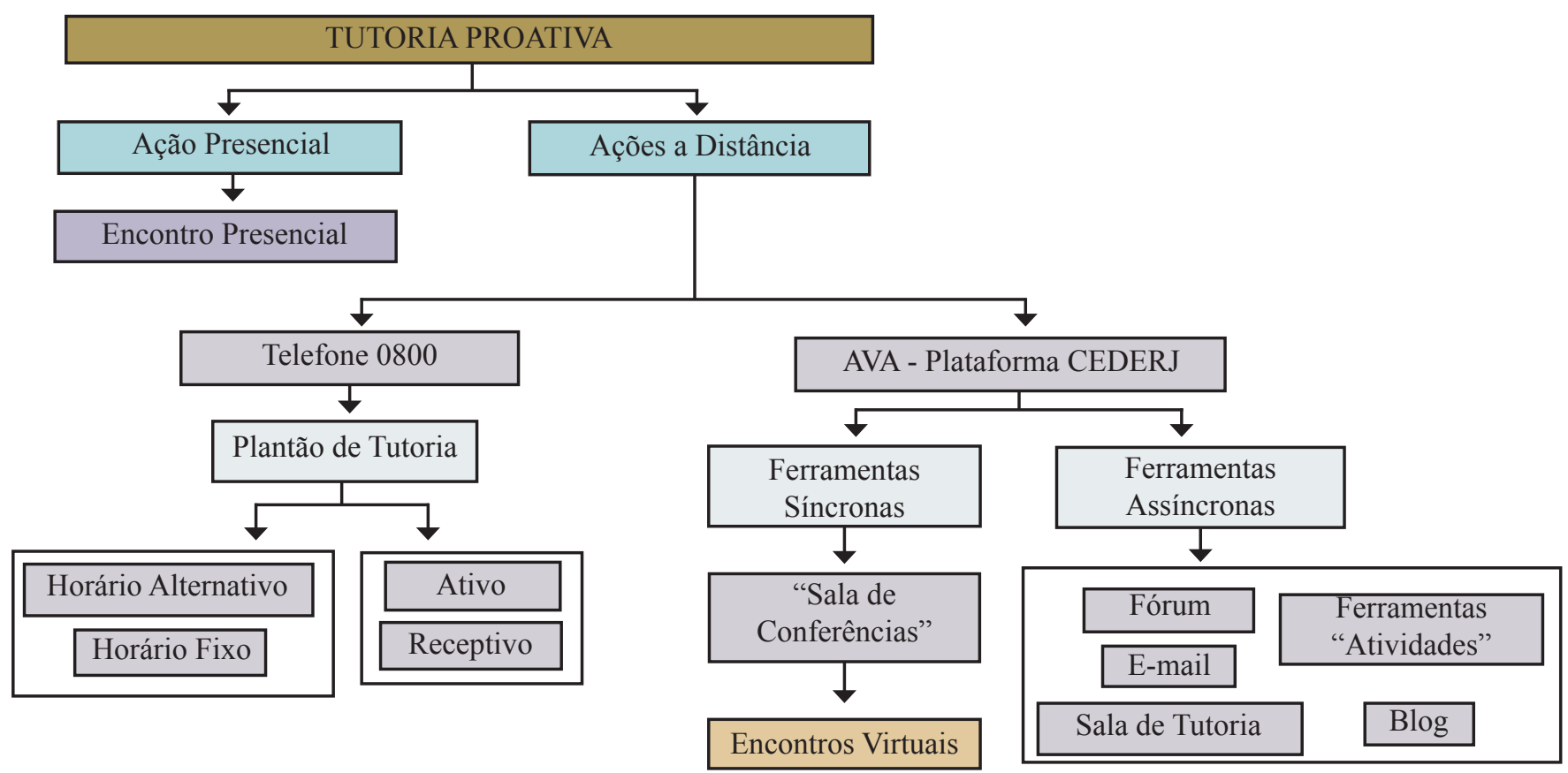

Figura 1: Esquema apresentando as ferramentas utilizadas para realização de tutoria proativa em ações presenciais e a distância.

Ação presencial: encontro presencial - O encontro entre tutores e aprendizes foi programado nos polos regionais para realização da ação presencial. Neste momento a proposta era estreitar laços através do contato pessoal com os tutores, conhecer os colegas do polo que faziam a mesma disciplina, tirar as dúvidas sobre a metodologia utilizada na disciplina além de discutir a proposta da atividade "Ludoteca".

Ações a distância: ferramentas assíncronas - Fórum: Com o objetivo de promover a integração entre aprendizes $e$ tutores foram realizados dois fóruns a cada semestre. No fórum inicial, cada aluno teve a oportunidade de falar um pouco de si e conhecer os tutores e outros aprendizes. O fórum "Ludoteca" teve como finalidade a formação dos grupos e a sugestão de temas para o desenvolvimento da atividade "Ludoteca". Sala de tutoria: Nesta ferramenta, os aprendizes podiam deixar dúvidas ou solicitar que um dos tutores entrasse em contato por telefone no horário em que pudessem interagir. e-mail: $\mathrm{O}$ e-mail foi utilizado para o primeiro contato com a disciplina. Neste momento os aprendizes encaminhavam seus telefones de contato e horários em que teriam maior disponibilidade de tempo. Também foi uma ferramenta usada pelos aprendizes para justificar ausências e tirar dúvidas. Através do e-mail, os tutores também informavam a disponibilização das atividades e encaminhavam próximo à data de entrega das atividades um e-mail de alerta.

Ferramentas síncronas - "Sala de Conferências". Na plataforma, um encontro virtual, agendado desde o início do semestre, foi realizado através desta ferramenta. A mesma conferência foi disponibilizada em dois dias e dois horários diferentes para facilitar a participação de todos os aprendizes. O tema desse encontro variou de acordo com os interesses dos aprendizes no decorrer do semestre.

Atendimento telefônico: Pelo 0800, os aprendizes puderam entrar em contato nos horários de plantão fixo da tutoria a distância sempre que julgaram necessário. Caso os horários disponibilizados para contato telefônico não fossem compatíveis com o do aprendiz, o mesmo pôde informar, através das ferramentas assíncronas, horários em que o contato fosse mais conveniente. A tutoria utilizou nestes casos o plantão de tutoria ativo com horários alternativos para atendimento telefônico.

Atividades Desenvolvidas - Atividades complementares e sequenciais foram propostas. Estas foram divididas em atividades individuais e colaborativas (Figura 2). 


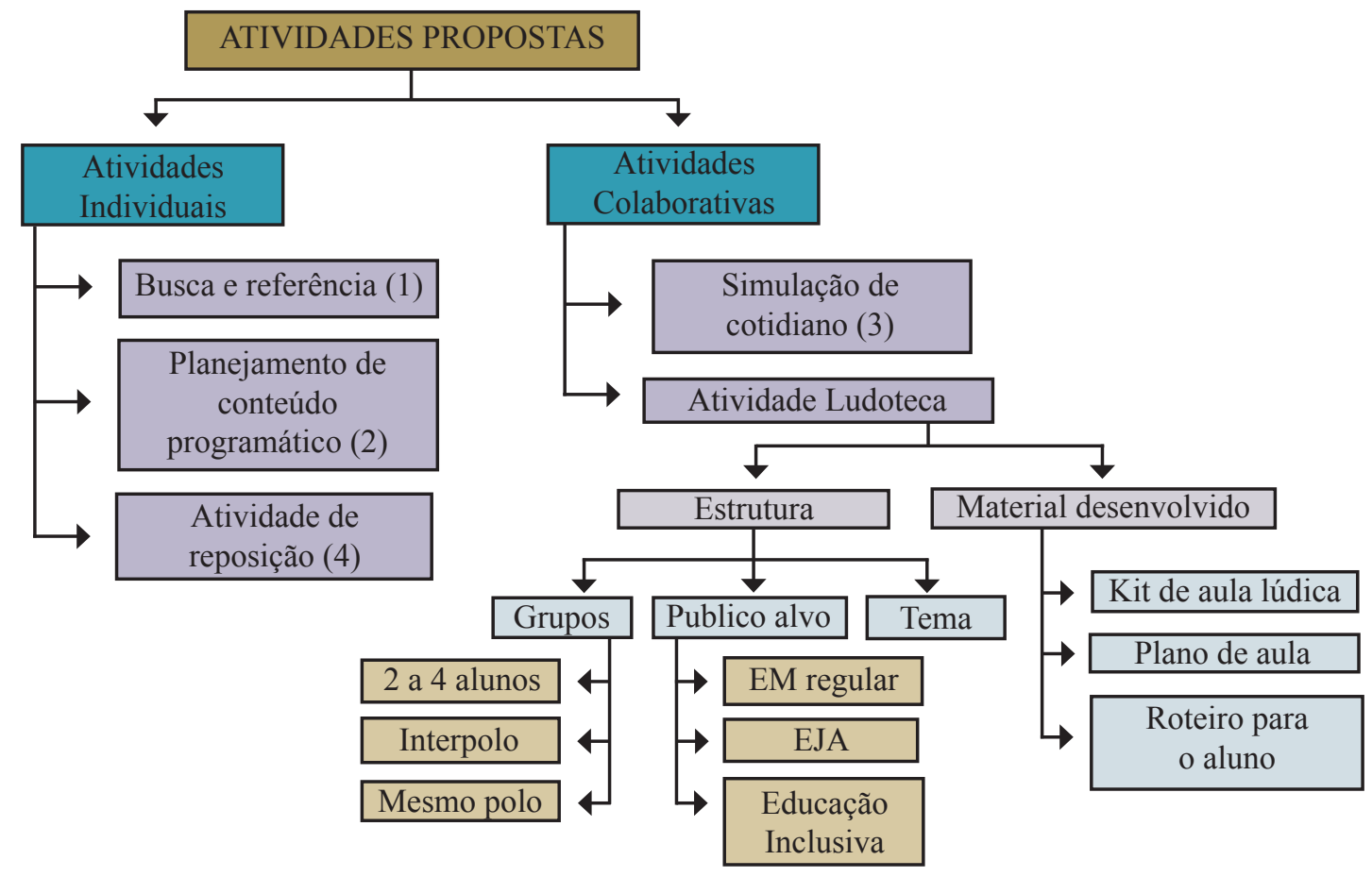

Figura 2: Esquema demonstrativo das atividades propostas pela disciplina.

Ordem cronológica de realização das atividades: A disciplina foi iniciada com fóruns, como mencionado anteriormente, porém apenas no intuito de aproximar aprendizes/aprendizes e aprendizes/ tutoria. Atividades individuais foram propostas utilizando a ferramenta "Atividades". A atividade 1 (Figura 2) foi proposta pela necessidade constante de atualização dos aprendizes e futuros professores além da ausência de material didático impresso. Um material complementar foi preparado e indicado. $\mathrm{O}$ mesmo explicou como utilizar sites de ferramentas de busca de informação científica como Portal CAPES, Google acadêmico, Scirus, Scielo, além de normas de citação bibliográfica. A atividade 2 propôs que os alunos/ aprendizes idealizassem o conteúdo programático de Biologia para o Ensino Médio, selecionando os assuntos que considerassem relevantes dentro do conteúdo de genética e biologia molecular. Prérequisitos necessários para cada um dos assuntos deveriam ser identificados assim como o momento em que ele deveria ser abordado, justificando o motivo da escolha do assunto. A atividade 4 foi feita por aprendizes que não cumpriram alguma das atividades individuais ou não puderam participar dos encontros e justificaram esta ausência.
Os aprendizes deveriam escolher um assunto dentro do conteúdo de Genética e Biologia Molecular, buscar artigos relacionados a este assunto e preparar uma aula teórica e um texto com referências sobre o tema. As atividades colaborativas (Figura 2) foram realizadas para valorizar a troca de experiência e conhecimento entre os aprendizes. $\mathrm{Na}$ atividade 3, os tutores expuseram em fórum situações do cotidiano da sala de aula, como dúvidas atuais de alunos sobre assuntos que foram divulgados na mídia. Assim, de forma colaborativa, os aprendizes deveriam discutir formas de esclarecer o aluno sem prejudicar o andamento do assunto abordado no momento. Já a atividade "Ludoteca" foi proposta logo no início e desenvolvida pelos aprendizes paralelamente às outras atividades propostas. O objetivo desta era desenvolver uma atividade lúdica sobre um tema de genética para um público-alvo determinado. Foi necessária a formação de grupos de 2 a 4 aprendizes, previamente organizado em um fórum. Foi sorteado o tema e o público alvo a que a aula lúdica se destina. A aula sempre deveria ser direcionada a alunos do Ensino Médio, porém poderia ser específica para EJA (Educação de Jovens e Adultos) ou Educação Inclusiva. Além da atividade lúdica, os aprendizes 
também deveriam preparar uma aula base e um roteiro para alunos e professores de Biologia, material este a ser entregue no polo regional.

Avaliação: Em contraponto à avaliação somativa, proposta pelo consórcio, neste trabalho foi utilizada a avaliação formativa, em que foram utilizados conceitos Satisfatório $(8,0$ a 10,0$)$, regular $(5,0$ a 7,9$)$ e não satisfatório $(0,0$ a 4,9). Neste modelo, onde buscouse valorizar as potencialidades do aprendiz por meio da autoaprendizagem, foram avaliadas as atividades, a participação nos fóruns $e$ nos encontros virtuais $e$ presenciais. Sendo que, em relação ao trabalho desenvolvido, o aluno teve direito a duas revisões de nota.

\section{Resultados e discussão}

Este trabalho analisou dados obtidos após observação de quatro turmas (2008.1, 2008.2, $2009.1 \mathrm{e}$ 2009.2) da disciplina Instrugen num total de 391 alunos matriculados, sendo 174 no ano de 2008 e 217 em 2009. Neste período o total de aluno que abandonaram a disciplina foi de 12,5\% (18,4\% em 2008 e $7,8 \%$ em 2009) (Tabela 1).

Tabela 1: Relação do número de alunos que abandonaram a disciplina

\begin{tabular}{|c|c|c|}
\hline Quantidade de alunos & $\mathbf{2 0 0 8}$ & $\mathbf{2 0 0 9}$ \\
\hline Matriculados & 174 & 217 \\
\hline Abandonos & 32 & 17 \\
\hline Abandono com matrícula trancada no CEDERJ & 6 & 2 \\
\hline Matriculados 1 vez e com 1 abandono & 4 & 12 \\
\hline Abandonos consecutivos & 9 & 3 \\
\hline Abandono com aprovação após 1 ano & 13 & - \\
\hline
\end{tabular}

A diminuição, em $58 \%$, do índice de abandono entre 2008 e 2009 foi atribuída à metodologia de tutoria proativa. Para que esse resultado fosse alcançado, além das análises do perfil dos aprendizes obtidos após a interação no fórum, considerou-se utilização de estratégias para melhorar a comunicação, incluindo um estímulo a interação após o encontro presencial.

As discussões nos fóruns, além de permitir diagnosticar um perfil dos aprendizes inscritos, também foram usadas para incentivar a permanência do aprendiz na disciplina como mais uma tentativa de estreitar os laços afetivos entre os aprendizes e entre aprendiz e tutoria. A importância da realização de fóruns online é descrita por Batista e Gobara (2008) quando discutem que essa ferramenta é fundamental para aumentar o interesse do aprendiz pela disciplina, e que o comprometimento dos tutores e aprendizes na organização do uso desta torna essa ferramenta relevante para o estímulo da interatividade. Segundo Pratt e Palloff (2004), o estímulo à participação dos aprendizes em ambientes online, que estimulam a aprendizagem colaborativa coletiva, é importante para sustentar a interatividade durante todo o curso. Em 2009, os contatos telefônicos e a proposta do encontro presencial alcançaram aprendizes que não interagiam no fórum.

Aos que interagiram, os fóruns possibilitaram que os aprendizes se conhecessem e se identificassem com outros aprendizes verificando fatos relevantes da vida pessoal e acadêmica $e$ as experiências, além de dificuldades em comum. Essa discussão permitiu a formação de um vínculo entre aprendizes e a proposta, pelos próprios, de várias soluções para superar as dificuldades em comum. Essa troca de experiências também foi observada por González e colaboradores (2009), ao analisar que a interação pôde ser facilitada pela similaridade de problemas vivenciados entre os aprendizes, além da compreensão do problema alheio e o planejamento de estratégia para vencer as dificuldades encontradas na realidade de cada um. O fórum permitiu que os aprendizes percebessem a importância da possibilidade de colaborar uns com os outros e interagir com tutores mais informalmente. A participação nos fóruns foi de 6,2 e 6,1 (participações em média por aprendiz em 2008 e 2009, respectivamente). 
A análise do perfil dos aprendizes também possibilitou adequar a proatividade da tutoria às necessidades dos aprendizes de forma personalizada a fim de manter a qualidade da troca de experiências e conhecimento. As variáveis modificadas incluem maior incentivo ao grupo de alunos/aprendizes com facilidade para uso de Tecnologias de Informação e Comunicação (TICs). O objetivo foi aumentar a frequência do acesso à plataforma e ao e-mail. Aqueles com dificuldades para uso de TICs foram estimulados a usar o contato por telefone.

Os grupos que moram distante do polo ou que trabalham e possuem pouca disponibilidade de tempo recebem uma maior atenção através do atendimento telefônico ativo. Assim, estes recebem telefonemas de apoio e/ou incentivo dos tutores. Essa última estratégia em especial é apoiada por Lopes e Xavier (2007) quando afirmam que o tutor deve ter uma postura que desperte no aprendiz confiança e esperança em suas próprias capacidades, tornando o aprendiz confiante e capaz. A individualização da proatividade baseada no perfil do grupo de alunos matriculados permitiu uma maior aproximação entre aprendiz e tutoria. Moran (2003) fala sobre a importância de estabelecer laços de confiança e um clima de apoio, incentivo e afeto com os aprendizes para que estes compreendam que a participação é fundamental. Isso resultou num maior aproveitamento em relação ao desempenho final dos aprendizes, como será apresentado ainda neste trabalho.
A inclusão do encontro presencial semestral no calendário da disciplina em 2009 favoreceu o contato entre tutor e aprendiz. Com este encontro a necessidade do tutor "buscar" o aprendiz foi reforçada. Essa atuação proativa da tutoria busca aumentar o "feedback" do aluno, incentivando a interatividade além de criar um laço afetivo entre tutor aprendiz. Conhecer os aprendizes pessoalmente permitiu saber como motivá-lo de maneira mais adequada. De acordo com Bonatto et al. (2008), o fortalecimento dos laços de afetividade e cumplicidade auxilia na superação de desafios de aprendizagem pessoal $e$ coletiva. Neste encontro foi possível esclarecer melhor as propostas da disciplina, assim como a estrutura formativa de avaliação e a importância da aprendizagem colaborativa.

De uma forma geral o encontro presencial minimizou dificuldades do contato virtual. Fato exposto por Oliveira (2007), o contato presencial tende a preencher lacunas que continuam em aberto após os estudos individuais, além de permitir uma liberdade nas próximas interações virtuais. $\mathrm{O}$ número de alunos que participaram do encontro está apresentado na Tabela 3. Foi registrada a participação de $67,2 \%$ dos alunos matriculados nos encontros e um reflexo positivo nas atividades e na interatividade após o encontro, demonstrada tanto através do desempenho dos mesmos quanto na participação no encontro virtual proposto (Tabela 2).

Tabela 2: Relação entre a presença dos aprendizes nos encontros propostos na disciplina, a quantidade de aprovação na disciplina, as médias das notas obtidas e o aumento da participação e do rendimento em notas

\begin{tabular}{|c|c|c|c|c|c|}
\hline & \multicolumn{2}{|c|}{2008} & \multicolumn{2}{|c|}{2009} & \multirow{2}{*}{$\begin{array}{c}\text { (\%) Aumento de } 2008 \text { para } 2009 \\
\text { Presença de alunos }\end{array}$} \\
\hline & $\mathrm{n}^{\mathrm{o}}$ de alunos & $(\%)$ & $\mathrm{n}^{\mathrm{o}}$ de alunos & $(\%)$ & \\
\hline Encontro presencial & - & - & 117 & $67,2 \%$ & - \\
\hline Encontro virtual & 81 & $59 \%$ & 124 & $72 \%$ & $22 \%$ \\
\hline Alunos aprovados & 117 & $85 \%$ & 164 & $94 \%$ & $10,1 \%$ \\
\hline Alunos regulares & 138 & $79,3 \%$ & 174 & $80,2 \%$ & $1,1 \%$ \\
\hline \multirow[t]{2}{*}{ Alunos matriculados } & 174 & $100 \%$ & 217 & $100 \%$ & - \\
\hline & \multicolumn{4}{|c|}{ Média das notas } & Rendimentos em notas \\
\hline Atividade "Ludoteca" & 7,7 & - & 8,5 & - & $10,4 \%$ \\
\hline Nota final & 8,3 & - & 9,8 & - & $18 \%$ \\
\hline
\end{tabular}


Em relação as atividades propostas pela disciplina, estas são uma opção de aprimorar o conhecimento dos aprendizes acerca dos temas abordados, exercitando a autoaprendizagem (responsabilidade pela condução da própria aprendizagem). Os conceitos obtidos pelos aprendizes após as orientações e revisões, quando necessárias, foram em sua maioria satisfatórios. Assim, as notas em atividades individuais permaneceram, em média, acima de 8,0. Além do dado somativo apresentado, um resultado satisfatório foi observado quanto a capacidade do aprendiz discutir sobre os temas abordados nas atividades em conferências virtuais propostas.

Duas das atividades propostas tinham como foco a aprendizagem colaborativa a partir da proposta da formação de grupos, a fim de permitir a transformação do saber coletivo através da interação, reflexão, discussão, crítica e ponderação, mais facilmente compreendidas quando partilhadas (BARBOSA, 2008). A atividade "Ludoteca", realizada em grupo, permitiu um aumento na percepção do aprendiz em relação a necessidade de incluir atividades lúdicas no ambiente de ensino. Segundo Muniz (2006), as atividades lúdicas são uma forma de buscar alternativas para novos métodos de estudo, criando situações estimuladoras e eficazes de aprendizagem. Esta opinião também foi reforçada por Souza (2009), ao afirmar que quando a prática pedagógica é trabalhada com o lúdico, os educadores são conduzidos a pensar em mudanças significativas para o meio educacional. A necessidade de formação de um grupo nessa atividade também incentivou a interação entre os aprendizes de um mesmo polo que muitas vezes nem se conhecem, além da interação entre aprendizes de polos diferentes.
Os resultados de 2008 apresentados na Tabela 3 mostram que a colaboração e interação entre alunos de polos diferentes se mostrou eficaz, independente da distância e falta de contato presencial entre eles. Em 2009 houve um aumento na quantidade de grupos de mesmo polo quando comparado com 2008. Esse fato foi atribuído à oportunidade que os aprendizes tiveram para formar os grupos entre os participantes no encontro presencial. Entretanto a média das notas dos grupos de mesmo polo e grupos interpolo não apresentou diferença significativa. Esse fato pode estar associado à maior interação com a tutoria, pois após o encontro presencial os aprendizes compreenderam a necessidade da interatividade. Segundo Moran (2004), o encontro físico entre tutor e aprendiz facilita o conhecimento mútuo estimulando a confiança entre as partes e com essa conquista fica mais fácil motivar os aprendizes e encaminhá-los para os pontos específicos que devem ser abordados. Quando comparado o rendimento em média de nota dos aprendizes que formaram grupos com aqueles que desenvolveram a atividade individualmente, observou-se que com o trabalho em grupo os aprendizes conseguiram alcançar notas mais elevadas. $\mathrm{O}$ fato de pertencer a um grupo como no caso apresentado é motivador para desencadear um processo significativo de aprendizagem (BARBOSA, 2008). Em um panorama final, o desempenho dos aprendizes em relação às notas na atividade "Ludoteca" após o encontro presencial foi $10,4 \%$ melhor em 2009 , quando comparado a 2008.

A disciplina ofereceu um espaço para discussão em grupo nos encontros virtuais. De acordo com Ferreira e Santos (2008), na aprendizagem colaborativa em ambientes virtuais é esperado que aprendizes con-

Tabela 3: Relação entre a classe de grupos formados e sua nota média na atividade "Ludoteca" em dois anos consecutivos

\begin{tabular}{|lcc|cc|}
\hline & \multicolumn{2}{c|}{$\begin{array}{c}2008 \\
\text { Número de grupos }\end{array}$} & \multicolumn{2}{c|}{ Média das notas } \\
& 11 & 7,4 & Número de grupos & Média das notas \\
\hline Número de grupos & 11 & 7,6 & 12 & 8,1 \\
Grupos de mesmo polo & 23 & 8,2 & 32 & 8,8 \\
Grupos interpolo & & 7,7 & 6 & 8,7 \\
\hline Média geral Ludoteca & & & 8,5 \\
\hline
\end{tabular}


tribuam com suas perspectivas para assuntos propostos e comentem as opiniões dos outros, o que acaba propiciando um conhecimento mais profundo e estruturado em comparação ao conhecimento adquirido individualmente. Corroborando a afirmativa anterior, os encontros desta disciplina estimularam a troca de conhecimentos e experiências de forma síncrona apresentando um resultado direto nos conhecimentos adquiridos pelos aprendizes ao longo da disciplina. A oportunidade de exercitar os conhecimentos adquiridos principalmente na atividade de "busca" estimulou os aprendizes a participar com mais intensidade e qualidade dos encontros virtuais. Muitas das discussões propostas nesse ambiente induziram o aprendiz a uma visão crítica do processo de ensino-aprendizagem, diminuindo equívocos e opiniões pré-moldadas intrínsecos de um ambiente formal de ensino. Os índices de participação podem ser observados na Tabela 3. A porcentagem de participação no encontro virtual foi de $59 \%$ em 2008 e $72 \%$ em 2009. Foi possível verificar um aumento de $22,03 \%$ na participação dos aprendizes de 2009 em relação a 2008, fato este que pode estar relacionado ao estímulo dado aos aprendizes nos encontros presenciais ocorridos em 2009. Esse incentivo teve como objetivo aumentar a interatividade e favoreceu o esclarecimento sobre a importância da aprendizagem colaborativa.

Ao final da disciplina a média geral atribuída aos alunos/aprendizes foi de 8,3 em 2008 e 9,8 em 2009. O desempenho dos aprendizes foi $18 \%$ melhor em 2009 quando comparado a 2008. De acordo com a Tabela 3, que resume os principais aspectos observados em relação à disciplina, fica claro que esta teve um crescimento em 2009 quando comparado a 2008. Os pontos relevantes a serem destacados foram o aumento da participação, apresentada em número de alunos, e a melhora do desempenho, apresentado em média de notas. Todas essas melhoras apresentadas em 2009 são resultados das mudanças implementadas na disciplina de acordo com as dificuldades observadas nos aprendizes e/ou resultados avaliativos obtidos em 2008, como apresentado por Vasconcelos e colaboradores (2008) que discutem o uso da avaliação como orientação para ajustes nas estratégias didáticas da disciplina.
Os resultados positivos observados na disciplina são também considerados pelos aprendizes ao responder o questionário "avaliativo" livre sobre a disciplina. As respostas apresentadas pelos aprendizes são uniformes e cerca de $88 \%$ dos aprendizes em 2008 e $99 \%$ em 2009 atribuíram notas máximas (4 e 5) para os quesitos avaliados.

\section{Considerações finais}

Analisando os dados obtidos neste trabalho podemse destacar alguns pontos relevantes. O principal deles é a importância da proatividade e personalização da tutoria a fim de atender as necessidades de cada aprendiz. Ao traçar o perfil do aprendiz utilizando recursos disponíveis na plataforma ou através do contato por telefone, foi possível tratá-lo de forma menos impessoal e verificar suas principais dificuldades, procurando sempre ajudá-lo a superá-las. A individualização da tutoria também minimizou o índice de abandono da disciplina já que o conhecimento das características de cada aluno permitiu adotar formas de interações mais adequadas.

A proatividade da tutoria estimulou constantemente a interatividade, estreitando relações, além de "buscar" o aluno incentivando-o, acabando por torná-lo mais participativo. Uma maior humanização através de encontros presenciais foi outro fator considerado importante para a criação $e$ o fortalecimento de vínculos de afetividade entre aprendiz/ aprendiz e entre tutor/aprendiz. Através de ações, presenciais e a distância, verificou-se um aumento nos índices de participação em atividades colaborativas propostas utilizando ferramentas síncronas, como os encontros virtuais. Também foi constatada uma melhora no desempenho nas atividades colaborativas desenvolvidas em grupo e, por fim, no desempenho geral do aprendiz.

Após a experiência adquirida com o desenvolvimento deste trabalho, foi possível concluir que a tutoria proativa deve considerar, além do estímulo da interatividade através das TICs, o lado humano para que o processo de ensino-aprendizagem utilizando a tutoria proativa tenha êxito. $\mathrm{O}$ aprendiz deve se sentir parte ativa deste processo, buscando, com auxílio o da tutoria, a melhor forma de utilizar suas habilidades $e$ competências para um maior aproveitamento. 


\section{Referências bibliográficas}

ALCÂNTARA, P. R.; SIQUEIRA, L. M. M.; VALASZI, S. Vivenciando a aprendizagem colaborativa em sala de aula: experiências no ensino superior. Revista Diálogo Educacional, Curitiba, v. 4, n. 12, maio/ago. 2004.

BARBOSA, Ana Cristina Lima Santos. Estratégias metodológicas inerentes a dinâmicas colaborativas on line. Disponível em: <http://www.abed.org.br/ congresso2008/tc/511200852108PM.pdf >. Acesso em: 05 jan. 2010.

BASSANI. Patrícia Scherer.; BEARH, Patricia Alejandra. Análise dasinteraçõesemambientesvirtuaisdeaprendizagem: uma possibilidade para avaliação da aprendizagem em EAD. Novas Tecnologias na Educação, Porto Alegre, v. 4, n. 1, p. 01 - 10, jul. 2006.

BASTOS, Luis Eduardo Marques. Avaliação do E-learning corporativo no Brasil. 2003. 264 f. Dissertação (Mestrado Profissionalizante em Administração), Universidade Federal da Bahia, Salvador-Ba, 2003. Disponível em: http://www. adm.ufba.br/pub/publicacao/5/MPA/2003/409/luis_ eduardo2.pdf. Acesso em: 22 dez. 2009.

BATISTA, ErlindaMartins; GOBARA, Shirley Takeco. Ofórum on-line e a interação em um curso a distância. Disponível em: <http://www.cinted.ufrgs.br/ciclo9/artigos/8cErlinda.pdf.>. Acesso em: 28 dez. 2009.

BELLONI, Maria Luiza. Educação a distância. Campinas, SP: Autores Associados, 1999.

BENETTI, Kelly Cristina; MELO, Pedro Antônio; VASQUES, Andressa Sasaki; NAKAYAMA, Marina Keiko; SPANHOL, Fernando José; DALMAU, Marcos Baptista Lopez; GIRARDI, Dante; TOSTA, Humberto Tonani. Atuação docente na Educação a Distância: uma análise das competências requeridas. Novas Tecnologias na Educação, Porto Alegre, v. 6 n. 1, jul. 2008. Disponível em:<http://www.cinted. ufrgs.br/renote/jul2008/artigos/3d_kelly.pdf $>$. Acesso em: 06 jan. 2010.
BONATTO, Benedito D.; MARTINS, Ronei X.; RAMOS, Luiz; SANTOS, Gamariel C., SILVA, Wanise W. E. A Importância da Afetividade nas Interações no Contexto da EaD. In: ESUD, 5., 2008. Disponível em: < http://200.169.53.89/download/CD\%20 congressos/2008/V\%20ESUD/trabs/t38647.pdf > . Acesso em: 05 jan. 2010.

CALABRI, Suely Brito de Souza. Novas perspectivas da EAD: um novo paradigma educacional. P@ rtes, São Paulo, v. 00 p. eletrônica, maio 2009. Disponível em: <http:/www.partes.com.br/educacao/ EADnovasperspecticas.asp>. Acesso em: 04 jan. 2010.

CHAVES, Eduardo. Ensino a distância: conceitos básicos, 1999. Disponível em: <http:/www. edutec.net/Tecnologia\%20e\%20Educacao/edconc. htm\#Ensino a Distância > . Acesso em: jan. 2010.

CLOSS, Lisiane Quadrado; BESSI, Vânia; ARAMBURU, Juliane; RUAS, Roberto Lima. Análise de Aspectos Relacionados à Aprendizagem em um Curso a Distância. Revista de Negócios, Blumenau, v. 13, n. 2, p. 48-57, abr./ jun. 2008. Disponível em: <http://proxy.furb.br/ojs/index. php/rn/article/view/969/838 > . Acesso em: 04 jan. 2010.

COSTA, Luciano Andreatta Carvalho; FRANCO, Sérgio Roberto Kieling. Ambientes virtuais de aprendizagem e suas possibilidades construtivistas. Novas Tecnologias na Educação, v. 3, n. 1. 2005. Disponível em: < http:// www.cinted.ufrgs.br/renote/maio2005/artigos/a25 ambientesvirtuais.pdf > . Acesso em: 02 jan. 2010.

CRIVELARO, Marisa. É preciso que sejamos proativos, não reativos: pensando a educação: o ser humano em formação. 2009. Disponível em: < http://marisacrivelaro. blogspot.com/2009/06/e-preciso-que-sejamosproativos-nao.html>. Acesso em: $27 \mathrm{dez} .2009$.

DAHMER, Alessandra. (2006). Um modelo para processo de curso. Tese de Doutorado, Universidade Federal do Rio Grande do Sul, Porto Alegre-RS, 132p. Disponível em <http:/www.lume.ufrgs.br/bitstream/ handle/10183/7365/000542837.pdf?sequence $=1>$. Acessado em: 03 de Janeiro de 2010. 
Aplicação de modelo de tutoria proativa na modalidade semipresencial de ensino a distância utilizando ferramentas de interatividade e personalização ——E

FERREIRA, Deller James; SANTOS, Gilberto Lacerda. Mediação do professor na aquisição e produção colaborativa do conhecimento na Web. Ciências \& Cognição. Vol 13 (3): 288-299, 2008. Disponível em: $<$ http://cienciasecognicao.tempsite.ws/revista/index. php/cec/article/view/81/75>. Acessado em: 05 de Janeiro de 2010.

FLORIANO, Sônia Inez Grüdtner; SCHUELTER, Giovana; RODRIGUES, GUAREZI, Rita de Cássia, GUAREZI, Mônica Menegaz; MATTOS, Márcia Maria. Acompanhamento ao estudante a distância: curso "iniciando um pequeno grande negócio - IPGN", uma experiência de capacitação em larga escala. RIED v. 8: 1 y 2, pp 253-268, 2005, < http:/www.utpl.edu.ec/ried/ portugues/images/pdfs/vol8-1-2/acompanhamiento_ estudante.pdf $>$. Acessado em 05 de janeiro de 2010.

GAIOSO, Natália Pacheco de Lacerda. O fenômeno da evasão escolar na educação superior no Brasil. Relatório técnico. Pró-Reitoria de Pós-Graduação e Pesquisa, Universidade Católica de Brasília. 2005.

GONZALEZ, Alberto Durán; ALMEIDA, Marcio José de; MENDONCA, Fernanda de Freitas. Percepções de participantes quanto ao curso de ativação de processos de mudança na formação superior de profissionais de saúde. Revista Brasileira de Educaçao Médica. Rio de Janeiro, v. 33, n. 2, Junho 2009. Disponível em: <http://www.scielo. br/scielo.php?script =sci_arttext\&pid $=$ S0100 $55022009000200003 \& \operatorname{lng}=e n \& n r m=i s o>$. Acessado em 06 de Janeiro de 2010.

JOHNSON, David; JOHNSON Roger. Learning together and alone: cooperative, competitive, and individualistic learning. Boston, MA: Allyn \& Bacon, 1997.

LAGUARDIA, Josué; PORTELA, Margareth Crisóstomo; VASCONCELLOS, Miguel Murat. Avaliação em ambientes virtuais de aprendizagem. Educação e Pesquisa, São Paulo, v. 33, n. 3, p. 513-530, set./dez. 2007. Disponível em: < http://www.scielo.br/scielo.php?pid=S151797022007000300009\&script $=$ sci_arttext\&tlng $=e s>$. Acessado em 05 de Janeiro de 2010.
LOPES, Maria CristinaL. Paniago;XAVIER, SelmaLúcia da Costa. A afetividade nas inter-relações professores e alunos no ambiente digital. Revista Brasileira de Aprendizagem Aberta e a Distância, São Paulo, pp. 1-17, Dez. 2007. Disponível em: <http://www.abed. org.br/revistacientifica/revista_pdf_doc/2007/2007_a_ afetividade_nas_inter_relacoes_maria_lopes.pdf $>$. Acessado em 05 de Janeiro de 2010.

MARTINS, Luiz Roberto Rodrigues. Educação superior a distância no Brasil: uma construção consorciada e em rede. Liinc em Revista, v.2, n.1, março 2006, p.7185. Disponível em: <http://revista.ibict.br/liinc/index. php/liinc/article/viewFile/205/120>. Acessado em 04 de Janeiro de 2010.

MEC/SEED. Ministério da Educação/Secretaria de ensino a distância. 1998. Indicações de Qualidade para cursos a distância. Última atualização em 2002. Disponível em: <http://mec.gov.br>. Acessado em: 15 de Dezembro de 2009.

MORAN, José Manuel. Aperfeiçoando os modelos de EAD existentes na formação de professores. Educação, Porto Alegre, v. 32, n. 3, p. 286-290, set./dez. 2009 b. Disponível em:<http://revistaseletronicas.pucrs.br/ ojs/index.php/faced/article/viewFile/5775/4196c > . Acessado em 03 de janeiro de 2010.

- O ensino superior a distância no Brasil. Educação \& Linguagem • V. 12 • N. 19 • 17-35, JAN.-JUN. 2009 a. Disponível em: < https://www. metodista.br/revistas/revistas-metodista/index.php/EL/ article/viewFile/811/879> Acessado em 03 de Janeiro de 2010.

- Modelos e avaliação do ensino superior a distância no Brasil. Educação Temática Digital, Campinas, v. 10, n. 2, p. 54-70, jun. 2009 c.

Os novos espaços de atuação do educador com as tecnologias. In ROMANOWSKI, J. P. et al. (Org.). Conhecimento local e conhecimento universal: diversidade, mídias e tecnologias na educação. Curitiba: Champagnat, . 2004. v. 2. p. 245-253. Disponível em: < http://www.smec.salvador.ba.gov.br/site/documentos/ 
espaco-virtual/espaco-edu-com-tec/artigos/os\%20 novos \%20espacos\%20de\%20atuacao\%20do\%20 educador....pdf > . Acesso em: 04 jan. 2010.

Textos sobre tecnologias de comunicação, 2003. Disponível em: <http://www.eca.usp.br/prof/ moran/textost.htm>. Acesso em: 05 jan. 2010.

MUNIZ, Paulina Jagher. A ludoteca colaborando com a formação de professores: uma experiência realizada no Instituto Superior de Educação de Guaratuba. UNIrevista, v. 1, n. 2, abr. 2006. Disponível em: < http:// www.unirevista.unisinos.br/_pdf/UNIrev_Muniz.pdf $>$. Acesso em: 06 jan. 2010.

NAVARRO Leila. Proatividade. Afinal, o que é isso? Vila Sucesso. In: NAVARRO, Leila. O que a universidade não ensina e o mercado de trabalho exige. São Paulo: Saraiva, 2008. (Coleção Sua Carreira / Seu Sucesso). Disponível em: <http:// vilamulher.terra.com.br/proatividade-afinal-o-quee-isso-5-1-37-68.html> Acesso em: 04 jan. 2010.

OLIVEIRA, Sheila da Costa. Encontros presenciais: uma ferramenta EAD? Novas Tecnologias na Educação , Porto Alegre, v. 5, n. 2, dez. 2007.

PALLOFF Rena; PRATT Keith. O aluno virtual: um guia para trabalhar com estudantes on-line. Tradução de Vinicius Figueira. Porto Alegre : Artmed. , 2004.

PETERS, O. A educação a distância em transição. São Leopoldo: Unisinos, 2004.

PIMENTEL, Renê, RIOS, Jocelma. Educação a distância e o seu grande desafio: o educando como sujeito de sua própria aprendizagem. In: ENCUENTRO IBEROAMERICANO DE EDUCACIÓN SUPERIOR A DISTANCIA, 12., Puerto Plata, 2007.

SILVA, Angela; SILVA, Christina. Avaliação da aprendizagem em ambientes virtuais: rompendo as barreiras da legislação. In: CONGRESSO DA ABED. Santos, 2008. Anais... Disponível em: <http://www. abed.org.br/congresso2008/tc/510200863228PM. pdf $>$. Acesso em: 03 jan. 2010.
SOUZA, Valdirene Araújo da Silva Souza. O lúdico: a sua importância ora aquisição da aprendizagem significativa. WebArtigos.com, 2009. Disponível em: <http:/www.webartigos.com/articles/13894/1/ o-ldico-a-sua-importncia-para-aquisio-daaprendizagem-significativa/pagina1.html>. Acesso em: 03 jan. 2010.

SOUZA, Matias Gonzalez. A arte da sedução pedagógica na tutoria em educação a distância. In: CONGRESSO INTERNACIONAL DE EDUCAÇÃOA DISTÂNCIA, 11., 2004, Salvador. Anais... Salvador: ABED, 2004. Disponível em: < http://lilianebarros. com/artigos/matias_gonzales.pdf $>$. Acesso em: 05 jan. 2010.

VALENTE, José. Educação a Distância: uma oportunidade para mudança no ensino, ead.br: Educação a distância no Brasil na era da Internet. São Paulo: Anhembi Morumbi; Universitária UFPE, 2000. p. 97-122.

VASCONCELOS, Francisco Herbert Lima; CAVALCANTE, Alisandra; OLIVEIRA, Eliana M.;SALES, Gilvandenys L.; ALMEIDA, Raquel F. S.; RODRIGUES, Herik Zednik; FILHO, José Aires de Castro; PEQUENO, Mauro Cavalcante. Avaliação Sócio-Interacionista Aplicada ao Contexto da EaD em Cursos de Graduação Semipresenciais Mediado por um Ambiente Virtual de Aprendizagem. In: Anais do XXVIII Congresso da SBC de 12 a 18 de Julho de 2008 - Belém do Pará. Disponível em: <http://www.proativa.virtual.ufc.br/publicacoes/a rtigos/1aa6d0579e503756b6bfbdef457f718a.pdf $>$. Acessado em 03 de Janeiro de 2010.

VOIGT, Emilio. A ponte sobre o abismo: a educação semipresencial como desafio dos novos tempos. Estudos Teológicos, v. 47, n. 2, p. 44-56, 2007. Disponível em: <www3.est.edu.br/publicacoes/ estudos.../ ET2007-2c_evoigt.pdf > . Acessado em: 04 de Janeiro de 2010. 
